\title{
PERENCANAAN TEKNIS SEQUENCE PENAMBANGAN GUNA MENUNJANG TARGET PRODUKSI PADA TRIWULAN II TAHUN 2020 PT DUTA ALAM SUMATERA
}

\section{MINING SEQUENCE TECHNICAL PLANNING TO SUPPORT PRODUCTION TARGET IN QUARTER II OF 2020 PT DUTA ALAM SUMATERA}

\author{
Muhammad Napis Fikri ${ }^{1)}$, Siti Hardianti ${ }^{2)}$ \\ ${ }^{1)}$ Program Studi Teknik Pertambangan Universitas Trisakti, 11440, Indonesia \\ ${ }^{2)}$ Program Studi Teknik Pertambangan Batubara Politeknik Akamigas Palembang, 30257, Indonesia \\ Corresponding Author E-mail: siti.hardianti2@pap.ac.id
}

\begin{abstract}
PT Duta Alam Sumatera (DAS) is a private company that has a production IUP with a concession area of 357 hectares. The mining system applied is open pit, using conventional mining methods. The pit design is done using the help of Minescape 5.7 software. Determination of the level geometry design and the road to be designed, namely bench height of 10 meters, bench width of 5 meters, bench slope of $45^{\circ}$ (single slope), $33^{\circ}$ (overall slope) applies to highwall and lowwall, while the design stage of the road is designed for the width of the straight haul road 10 meters, the width of the haul road at 12 meters, and the maximum slope of the road is $8 \%$. The design of the second quarter pit design has a $5.20 \mathrm{Ha}$ area, so that the results of overburden cutting material obtained in the second quarter pit design are 305,284 BCM, and for coal is 52,029 ton with A bituminous coal seam quality with SR 5.8: 1. Obtained the need for tools for overburden stripping, it takes 2 units of PC 400 digging and loading equipment and 8 units of CWB dumptruck for overburden, while for Zaxis 470 fleet excavator and 4 units of CWB dumptruck. The design pit was tested in the Safety Factor (FK) for slope stability in two sections with two dimensions to obtain a FK with a value of 6.074 in section A - A ', and 2.909 in section B - B', so the slope is said to be safe.
\end{abstract}

Keywords: Pit Design, Tool Requirements, Safety Factor

Abstrak: PT Duta Alam Sumatera (DAS) merupakan salah satu perusahaan swasta yang memiliki IUP produksi dengan lahan konsesi sebesar 357 hektar. Sistem penambangan yang diterapkan adalah open pit, menggunakan metode penambanagn secara konvensional. Desain pit dilakukan menggunakan bantuan software minescape 5.7. Penentuan desain geometri jenjang dan jalan yang akan dirancang yaitu tinggi bench 10 meter, lebar bench 5 meter, kemiringan bench $45^{\circ}$ (single slope), $33^{\circ}$ (overall slope) berlaku terhadap highwall dan lowwall, sedangkan tahapan desain jalan dirancang untuk lebar jalan angkut lurus 10 meter, lebar jalan angkut pada tikungan 12 meter, dan kemiringan jalan maksimum 8\%. Bentuk desain pit triwulan II memiliki luas area plan 5,20 Ha, sehingga didapatkan hasil cutting material overburden pada desain pit triwulan II sebesar 305.284 BCM, dan untuk batubara sebesar 52.029 ton dengan kualitas seam batubara A bituminous deangan SR 5,8:1. Didapatkan kebutuhan alat untuk pengupasan overburden dibutuhkan 2 unit alat gali-muat PC 400 dan alat angkut untuk overburden sebanyak 8 unit dumptruck CWB, sedangkan untuk fleet excavator Zaxis 470 dan untuk alat angkutnya sebanyak 4 unit dumptruck CWB. Design pit pada triwulan II dilakukan pengujian Faktor Keamanan (FK) kestabilan lereng di dua section penampang dua dimensi sehingga didapat FK dengan nilai 6,074 pada section A - A', dan 2,909 pada section B - B', sehingga lereng dikatakan aman.

Kata kunci : Desain Pit, Kebutuhan Alat, Faktor Keamanan

\section{PENDAHULUAN}

\subsection{Latar Belakang}

Batubara adalah salah satu sumber energi alternatif yang menyumbang ketersedian energi pada saat ini baik sebagai pembangkit tenaga listrik, industri pembuatan semen, peleburan biji besi dan baja, pembuatan kokas dan masih banyak lagi. Dapat dilihat dari permintaan batubara dari pasar domestik maupun mancanegara yang meningkat tiap tahunnya.

PT Duta Alam Sumatera (DAS) merupakan salah satu perusahaan swasta yang bergerak pada bidang usaha pertambangan batubara di Indonesia, hasil produksi batubara oleh PT Duta Alam Sumatera umumnya masih digunakan untuk kebutuhan domestik. PT Duta Alam Sumatera berlokasi di Desa Tanjung Baru, Kecamatan Merapi Barat, 
Kabupaten Lahat, Sumatera Selatan dan memiliki IUP produksi dengan lahan konsesi sebesar 357 hektar. Dalam kegiatan penambangan batubara PT Duta Alam Sumatera bekerja sama dengan salah satu perusahaan kontraktor yaitu PT Wirasana Energi Bara (WEB). Sistem penambangan yang diterapkan oleh PT Duta Alam Sumatera adalah sistem penambangan terbuka yang biasa disebut dengan open pit, menggunakan menggunakan metode penambanagn secara konvensional, yaitu penambangan yang dilakukan dengan menggunakan excavator dan dump truck dan hanya memiliki satu pit yaitu pit DAS. Rencana Produksi PT Duta Alam Sumatera pada pit DAS khususnya kontraktor mereka yaitu PT Wirasana Energi Bara untuk triwulan II adalah sebesar 300.000 BCM overburden dan 50.000 ton batubara. Pada triwulan I PT DAS merencanakan target produksi pada kontraktor mereka PT WEB sebesar 50.000 ton batubara dan $300.000 \mathrm{Bcm}$ overburden. Namun, PT WEB hanya menghasilkan produksi $43.586 \mathrm{TON}$ batubara dan 237.893 BCM overburden. Oleh karena itu, pada penelitian ini dilakukan pemodelan pit.

Dalam mencapai target produksi tersebut, maka ada beberapa hal yang harus dilakukan yaitu mendesain kembali pit, menganalisis faktor yang mempengaruhi produksi, serta meminimalisir faktor yang menghambat ketercapaian produksi guna mencapai target produksi yang telah ditetapkan. Pada penelitian ini akan dilakukan perencanaan kembali desain pit yang mempertimbangkan kepada aspek-aspek teknis dan forecast plan kebutuhan alat-gali muat dan alat angkut yang dibutuhkan serta menganalisis faktor keamanan dari design periode triwulan II Tahun 2020.

\subsection{Rumusan Masalah}

Penelitian ini dilakukan karena adanya permasalahan mengenai bagaimana proporsi blending yang tepat untuk memenuhi spesifikasi batubara pasar ekspor tujuan Filipina pada bulan Mei 2019 dan bagaimana stock akhir batubara pada bulan tersebut.

\subsection{Batasan Masalah}

Batasan masalah dalam penelitian ini, adalah:

1. Periode yang dilakukan hanya pada sequence triwulan 2 April s.d. Juni tahun 2020 PT Duta Alam Sumatera.

2. Rancangan sequence penambangan hanya berdasarkan kajian teknis/tidak melibatkan biaya.

3. Design yang dibuat hanya meliputi design pit (jalan, sump, bench) tanpa mengikutsertakan design disposal dan stockpile .

4. Geometri bench mengikuti rekomendasi dari tim geoteknik PT Duta Alam Sumatera.

5. FK yang diuji menggunakan software Slope V.6.

6. Forecast kebutuhan alat meliputi alat loader (PC 400 \& Zaxis 470), hauler (DT CWB \& DT Daeewo) dan dozer (D8R \& D85ESS) guna menunjang produksi dari desain yang telah dibuat.

\subsection{Tujuan Penelitian}

Tujuan yang ingin dicapai dalam penelitian ini adalah:

1. Membuat design sequence penambangan periode bulan April-Juni 2020 berdasarkan acuan target produksi.

2. Membuat forecast plan kebutuhan alat guna menunjang target produksi dari desain yang telah dibuat.

3. Menganalisis faktor-faktor yang mempengaruhi produksi dan menganalisis faktor keamanan dari desian yang telah dibuat.

\subsection{Manfaat Penelitian}

Manfaat dalam penelitian ini adalah menghasilkan rancangan dan sequence penambangan batubara untuk memenuhi target produksi bulanan di PT Duta Alam Sumatera.

\section{TEORI DASAR}

2.1. Ruang Lingkup Perencanaan Tambang

Agar perencanaan tambang dapat dilakukan dengan lebih mudah, masalah ini biasanya dibagi menjadi tugas-tugas sebagai berikut: 
1. Pembuatan Design dan Penentuan Batas Pit

Menentukan batas akhir dari kegiatan penambangan (ultimate pit limit) untuk suatu cadangan batubara. Ini berarti menentukan berapa besar cadangan batubara yang akan ditambang (tonase dan kadarnya) yang akan memaksimalkan nilai bersih total cadangan batubara tersebut. Dalam penentuan batas akhir dari pit, nilai waktu dari uang belum diperhitungkan. Layout dan design tambang beserta penentuan batas penambangan antara lain:

1. Layout dan design tambang:
a. Desain pit,
b. Desain jalan (ramp),
c. Desain jenjang (bench), dll.

2. Penentuan batas penambangan:
a. Optimum stripping ratio,
b. Batas penambangan,
c. Batas lain: sungai, jalan, dll.

\section{Perencanaan Tambang Berdasarkan Urutan Waktu}

Dengan menggunakan sasaran jadwal produksi, gambar atau peta-peta rencana penambangan dibuat untuk setiap priode waktu (biasanya per tahun). Peta-peta ini menunjukkan dari bagian mana di dalam tambang kemiringan batubara dan waste untuk lahan tersebut. Rencana penambangan tahunan ini sudah cukup rinci, di dalamnya sudah termasuk pula jalan angkut dan ruang kerja alat, sedemikian rupa sehingga merupakan bentuk yang dapat ditambang. Peta rencana pembuangan lapisan tanah penutup (disposal) dibuat pula untuk periode waktu yang sama sehingga gambaran keseluruhan dari kegiatan penambangan dapat terlihat.

\section{Pemilihan Alat}

Berdasarkan peta-peta rencana penambangan dan penimbunan lapisan tanah penutup dibuat profil jalan angkut untuk setiap periode waktu, dengan mengukur profil jalan angkut ini, kebutuhan armada alat gali-muat dapat dihitung untuk setiap periode (setiap bulan), serta alat-alat bantu lainnya (dozer, grader, dll).

Parameter pemilihan alat, yaitu:

a. Kondisi tanah dan batuan,
b. Target produksi,
c. Produktivitas,
d. Jumlah alat,
e. Karakteristik material,
f. Tebal dan kemiringan ore,
g. Jam kerja,
h. Shift kerja,
i. Jarak angkut,
j. Topografi, dan
k. Cuaca.

\section{METODOLOGI PENELITIAN}

\subsection{Jenis Penelitian}

Jenis penelitian dilakukan adalah jenis penelitian deskriptif karena melakukan pengamatan langsung di lapangan dengan bentuk data kuantitatif. Penelitian kuantitatif adalah suatu proses menemukan pengetahuan yang menggunakan data berupa angka, sebagai media untuk menganalisis keterangan mengenai apa yang ingin diketahui.

\subsection{Tempat dan Waktu Penelitian}

Penelitian ini dilakukan pada tanggal 24 Februari sampai dengan 24 April 2020 di PT Duta Alam Sumatera. IUP Pertambangan PT Duta Alam Sumatera secara administrasi termasuk ke dalam wilayah Desa Payo Kecamatan Merapi Barat, Kabupaten Lahat, Propinsi Sumatera Selatan.

\subsection{Metode Penelitian}

1. Studi literatur

Tahap studi literatur, yaitu memenuhi sumber informasi yang berasal dari referensi maupun data perusahaan yang berkaitan dengan tujuan penelitian. Studi literatur ini dilakukan sebelum dan selama penelitian berlangsung. Dengan informasi yang dikumpulkan antara lain :

a. Materi perencanaan tambang,

b. Materi forecast plan,

c. Tutorial Software MineScape 5.7, dan

d. Tutorial Slide V6.0.

2. Pengamatan lapangan

Pengamatan ini dilakukan secara langsung di lapangan dengan mengamati lokasi area pit di PT Duta Alam Sumatera khususnya pada front kerja kontraktor, yaitu 
PT Wirasana Energi Bara dengan permasalahan yang akan dibahas, antara lain :

a. Pengamatan terhadap daerah penambangan PT Duta Alam Sumatera khususnya PT Wirasana Energi Bara, alatalat yang digunakan, kinerja alat yang digunakan, efisiensi kerja, dan faktorfaktor yang mempengaruhi produksi.

b. Pengamatan dan pencatatan secara langsung faktor teknis dilapangan seperti elevasi, dimensi bench, geometri jalan, cycle time, lost time, dan faktor yang mempengaruhi ketidakcapaian produksi.

\section{Diskusi}

Metode ini dilakukan dengan cara berdiskusi mengenai hal-hal yang berkaitan dengan keadaan lapangan untuk memperoleh data-data yang diperlukan dalam penelitian ini. 4. Pengambilan data

Data diperoleh dari pengamatan langsung dilapangan (data primer) dan literature-literatur yang berhubungan dengan permasalahan yang ada (data sekunder). Pengambilan data di lapangan terbagi menjadi dua, yaitu:

a. Data primer

Data primer adalah data yang diperoleh dari melakukan pengamatan langsung ke lapangan dan melakukan wawancara terhadap pegawai setempat, data tersebut diantaranya, yaitu :

a) Cycle time,

b) Data pengamatan visual kemajuan penambangan, dan

c) Data kemiringan dan penyebaran. batubara

\section{b. Data sekunder}

Data sekunder ialah merupakan bagian dari data pendukung yang didapatkan berdasarkan literatur-literatur yang berhubungan dengan permasalahan yang ada. Pengambilan data tergantung dari jenis data yang dibutuhkan, yaitu:

a) Data rencana produksi tahun 2020 PT Duta Alam Sumatera,

b) Data topografi,

c) Data rekomendasi geometri jenjang dan geometri jalan,

d) Data kualitas batubara, e) Ketersediaan alat $(P A, M A$, dan $U A)$,

f) Data produksi aktual di lapangan,

g) Desain pit longterm,

h) Spesifikasi alat mekanis,

i) Lebar jalan angkut,

j) Data curah hujan, dan

k) Data working hours plan.

5. Pengolahan dan analisis data

Pengolahan data dilakukan secara manual terhadap data yang diperoleh dari pengamatan lapangan maupun data perusahaan dengan panduan dari dasar teori yang sudah diperoleh dari bahan-bahan pustaka yang menunjang.

\section{HASIL DAN PEMBAHASAN}

Perencanaan teknis desain pit meliputi desain geometri jenjang, geometri jalan, dan forecast plan kebutuhan alat gali-muat dan alat angkut yang digunakan pada periode triwulan II guna menunjang rencana produksi tahun 2020. Perencanaan teknis desain pit di PT Duta Alam Sumatera dilakukan untuk melanjutkan desain pit yang telah ada pada periode triwulan sebelumnya (triwulan $I$ 2020). Untuk geometri jenjang dan jenis alat gali-muat dan alat angkut yang digunakan mengikuti perencanaan teknis yang sudah terealisasikan di lapangan. Rencana produksi material (overburden dan batubara) di PT Duta Alam Sumatera tahun 2020 sebesar 1.200.000 BCM overburden dan 200.000 ton batubara dengan stripping ratio rata-rata 6:1 seprti pada Tabel 4.1.

Tabel 4.1 Rencana Produksi Material PT DAS pada pit WEB Tahun 2020

\begin{tabular}{|c|c|c|c|}
\hline Triwulan & Overburden (BCM) & Coal (TON) & Stripping Ratio \\
\hline I & 300.000 & 50.000 & $1: 6$ \\
\hline II & 300.000 & 50.000 & $1: 6$ \\
\hline III & 300.000 & 50.000 & $1: 6$ \\
\hline IV & 300.000 & 50.000 & $1: 6$ \\
\hline Total & 1.200 .000 & 200.000 & $1: 6$ \\
\hline
\end{tabular}

Daerah penelitian di PT Duta Alam Sumatera memiliki luas 3,05 Ha dengan kontur tertinggi sebesar $100 \mathrm{mdpl}$ dan kontur terendah dengan elevasi 73 mdpl menggunakan metode penambangan open pit 
mining (tambang terbuka) (Gambar 4.1). Proses kegiatan penambangan batubara dan overburden dilakukan secara conventional dengan menggunakan alat gali-muat backhoe (Komatsu PC400 dan Hitachi 470LC) dan alat angkut dumptruck (DT Tata Nouvus Daeewo dan DT Nissan Diesel CWB450) yang dilakukan penimbunan (disposal) di luar area pit (out pit) dengan jarak $1000 \mathrm{M}$ sedangkan untuk jarak posisi stockpile $3100 \mathrm{M}$ dari front penambangan

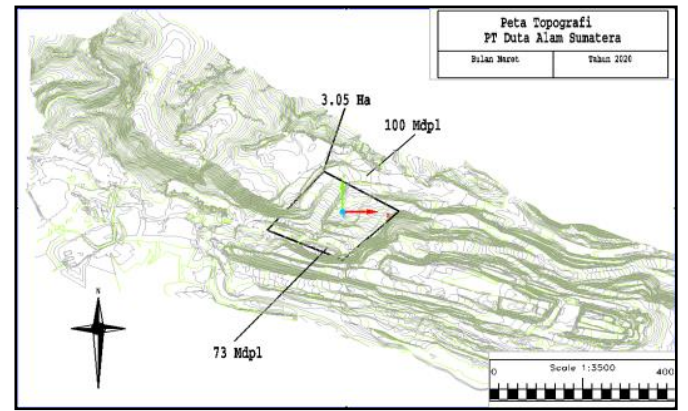

Gambar 4.1 Peta Topografi Maret 2020

Penggunaan metode open pit ini dilakukan karena kondisi dari endapan seam batubara memiliki kemiringan yang signifikan yaitu $70-90^{\circ}$ dengan dip ke arah selatan-utara dan strike endapan batubara ke arah timurbarat dan terdapat 3 seam utama batubara, yaitu seam A, B, dan C. (Gambar 4.2).

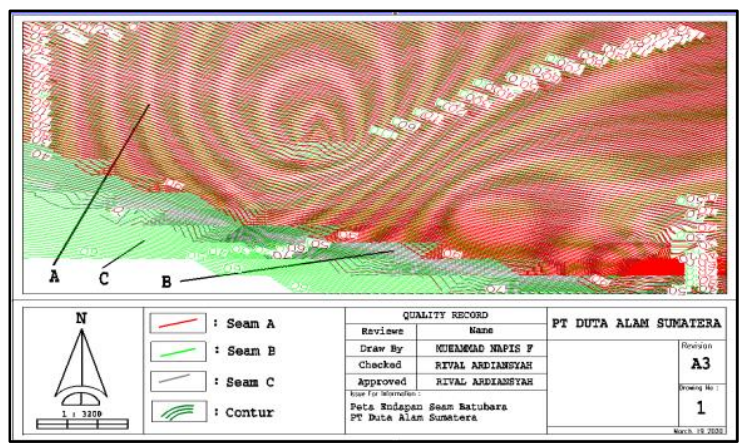

Gambar 4.2 Kontur Endapan Seam Batubara PT Duta Alam Sumatera

Tahapan batas awal penambangan batubara triwulan II mengacu terhadap desain pit end of month (EOM) tahun 2020 dan boundary pit (batas penambangan) disesuaikan terhadap stripping ratio (SR) rata-rata rencana produksi batubara 200.000 ton sebesar 6:1
(Gambar 4.3), dan arah kemajuan penambangan berdasarkan dip dan strike endapan seam batubara, yaitu Selatan-Utara dan Timur-Barat. Kegiatan penambangan di PT Duta Alam Sumatera dengan menggunakan alat dari kontraktor mereka PT Wirasana Energi Bara berupa:

Tabel 4.2 Alat yang Dimiliki PT WEB

\begin{tabular}{|l|c|c|l|}
\hline \multicolumn{1}{|c|}{ Alat } & Fleet & Unit & Status \\
\hline $\begin{array}{l}\text { Excavator } \\
\text { Komatsu } \\
\text { PC400 }\end{array}$ & Coal Getting & 1 & $\begin{array}{l}\text { Unit } \\
\text { Loading }\end{array}$ \\
\hline $\begin{array}{l}\text { Excavator } \\
\text { Komatsu } \\
\text { PC400 }\end{array}$ & Overburden & 1 & $\begin{array}{l}\text { Unit } \\
\text { Loading }\end{array}$ \\
\hline $\begin{array}{l}\text { Excavator } \\
\text { Hitachi } \\
\text { Zaxis470 }\end{array}$ & Overburden & 1 & $\begin{array}{l}\text { Unit } \\
\text { Loading }\end{array}$ \\
\hline $\begin{array}{l}\text { DT Tata } \\
\text { Daeewo }\end{array}$ & Coal Getting & 5 & $\begin{array}{l}\text { Unit } \\
\text { Hauling }\end{array}$ \\
\hline $\begin{array}{l}\text { DT Nissan } \\
\text { Diesel } \\
\text { CWB }\end{array}$ & Overburden & 10 & $\begin{array}{l}\text { Unit } \\
\text { Hauling }\end{array}$ \\
\hline $\begin{array}{l}\text { Excavator } \\
\text { Kobelco } \\
\text { SK200 }\end{array}$ & Coal Getting \\
DozR & 1 & $\begin{array}{l}\text { Unit } \\
\text { Penunjang }\end{array}$ \\
\hline
\end{tabular}

\section{Design Pit WEB Longterm}

Design pit logterm direncanakan dengan mempertimbangkan rekomendasi geoteknik dari PT Duta Alam Sumatera, yaitu dengan tinggi bench $10 \mathrm{~m}$ dan lebar bench $5 \mathrm{~m}$ dengan single slope $45^{\circ}$ untuk high wall dan side wall single slope $35^{\circ}$, sedangkan untuk sisi low wall mengikuti kontur dari floor seam batubara A. Design pit longterm dirancang dengan batas-batas sebagai berikut:

1. Batas kedalaman, kontur struktur floor seam batubara elevasi $30 \mathrm{mdpl}$.

2. Batas Utara, berbatas dengan high wall.

3. Batas Selatan, berbatas dengan seam B. 
4. Batas Barat, berbatas dengan pit kontraktor PT DAS yaitu PT CRM.

5. Batas Timur, berbatas dengan sump.

Design pit longterm (Gambar 4.3) yang dihasilkan memiliki luas area plan 8,37 Ha, dengan elevasi tertinggi $100 \mathrm{mdpl}$ dan elevasi terendah mencapai $30 \mathrm{mdpl}$. Density insitu batubara pada penambangan di pit WEB yaitu $1,3 \mathrm{~m}^{3} /$ ton. Jumlah volume overburden dan batubara pada pit longterm WEB sebesar 1.200.000 BCM dan 200.000 ton dengan stripping ratio $(\mathrm{SR})$ yang dihasilkan $6: 1$.

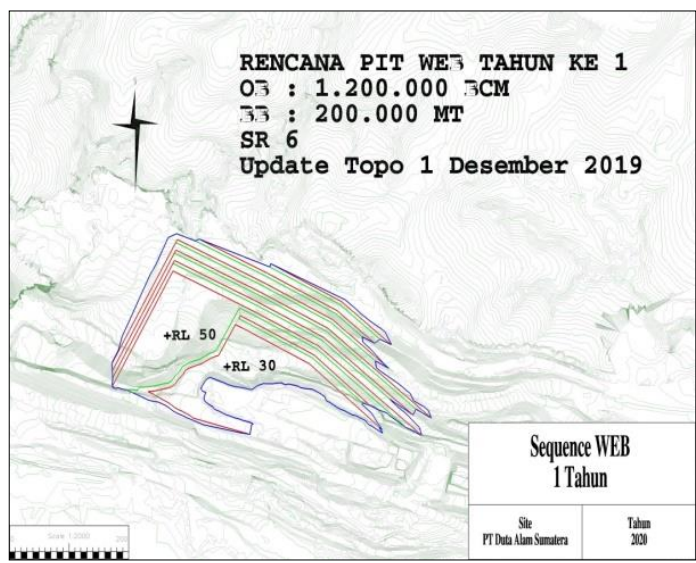

Gambar 4.3 Peta sequence PT WEB Periode

Triwulan II

Desain pit yang telah dirancang akan diuji faktor keamanan (FK) kestabilan lereng menggunakan software Slide V.6.0 metode Bishop dengan parameter pengujian material berupa densitas, sudut geser dalam, dan kohesi material.

Pengujian FK dilakukan pada periode triwulan II dimana adanya penambahan elevasi kedalaman serta adanya penambahan luas bukaan pit yang berpengaruh terhadap luas daerah tangkapan air hujan. Oleh karena itu, desain pit pada triwulan II dijadikan sebagai acuan pengujian FK. Tahapan forecast plan kebutuhan alat gali-muat dan alat angkut dilakukan untuk menunjang hasil cutting overburden dan batubara dari hasil desain pit triwulan II tahun 2020 dengan mengolah data berupa data cycle time, data working hours plan of overburden removal, working hours plan of coal getting, dan data physical avaibility plan masing-masing alat, sehingga didapatkan produksi masing-masing alat dan kuantitas alat yang dibutuhkan pada triwulan II tahun 2020.

\section{Design Pit WEB Triwulan I \& II Tahun 2020}

a. Periode Triwulan I

Periode triwulan I ini sebagai situasi awal dan menjadi acuan bagi penulis mendesain periode triwulan II, Design pit triwulan I dirancang dengan luas area plan 3,73 Ha guna menunjang target produksi pada periode tersebut yaitu sebesar $300.000 \mathrm{BCM}$ overburden dan 50.000 ton batubara. Bentuk design pit triwulan I dari PT Duta Alam Sumatera, yaitu dengan tinggi bench $10 \mathrm{~m}$ dan lebar bench $5 \mathrm{~m}$ dengan single slope $45^{\circ}$ untuk high wall dan side wall single slope $33^{\circ}$, sedangkan untuk sisi low wall di kedalaman elevasi 70 mdpl dengan arah penambangan dari arah tenggara ke barat laut. Pada design pit triwulan I memiliki 2 lajur jalan dengan lebar keseluruhan $12 \mathrm{~m}$ yang memiliki kemiringan (grade) 8-9\%. Sehingga didapatkan hasil cutting material overburden dan batubara sebesar 310.846 BCM dan 52.074 ton, sehingga stripping ratio yang didapatkan 5,9:1. Pada periode triwulan I dengan setting fleet yaitu 3 fleet dimana 1 fleet batubara dan 2 fleet overburden guna menunjang design pit triwulan I seperti pada Tabel 4.3.

Tabel 4.3 Setting Fleet Triwulan I

\begin{tabular}{|l|c|c|l|}
\hline \multicolumn{1}{|c|}{ Alat } & Fleet & Unit & \multicolumn{1}{|c|}{ Status } \\
\hline $\begin{array}{l}\text { Excavator } \\
\text { Komatsu } \\
\text { PC400 }\end{array}$ & Coal Getting & 1 & $\begin{array}{l}\text { Unit } \\
\text { Loading }\end{array}$ \\
\hline $\begin{array}{l}\text { Excavator } \\
\text { Komatsu } \\
\text { PC400 }\end{array}$ & Overburden & 1 & $\begin{array}{l}\text { Unit } \\
\text { Loading }\end{array}$ \\
\hline $\begin{array}{l}\text { Excavator } \\
\text { Hitachi Zaxis } \\
470\end{array}$ & Overburden & 1 & $\begin{array}{l}\text { Unit } \\
\text { Loading }\end{array}$ \\
\hline $\begin{array}{l}\text { DT Tata } \\
\text { Daeewo }\end{array}$ & Coal Getting & 4 & $\begin{array}{l}\text { Unit } \\
\text { Hauling }\end{array}$ \\
\hline $\begin{array}{l}\text { DT Nissan } \\
\text { Diesel CWB }\end{array}$ & Overburden & 8 & $\begin{array}{l}\text { Unit } \\
\text { Hauling }\end{array}$ \\
\hline
\end{tabular}




\begin{tabular}{|l|c|c|c|}
\hline \multicolumn{1}{|c|}{ Alat } & Fleet & Unit & Status \\
\hline $\begin{array}{l}\text { Excavator } \\
\text { Kobelco } \\
\text { SK200 }\end{array}$ & Coal Getting & 1 & $\begin{array}{l}\text { Unit } \\
\text { Penunjang }\end{array}$ \\
\hline $\begin{array}{l}\text { Dozzer D8R } \\
\text { (Ripping) }\end{array}$ & Overburden & 1 & $\begin{array}{l}\text { Unit } \\
\text { Penunjang }\end{array}$ \\
\hline
\end{tabular}

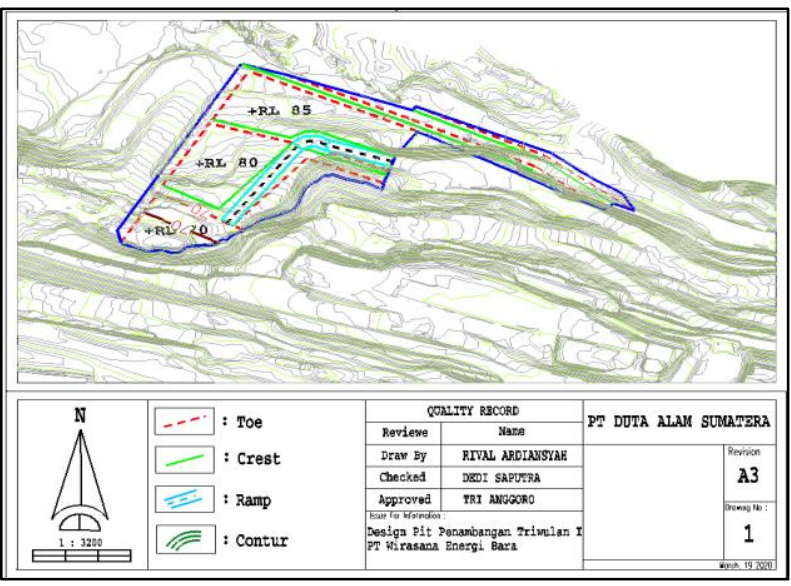

Sumber : Enginering PT DAS

Gambar 4.4 Design Pit WEB Periode Triwulan I

\section{b. Periode Triwulan II}

Desain pit pada penambangan batubara triwulan II dirancang oleh peneliti untuk menunjang rencana produksi sebesar 300.000 BCM untuk overburden, dan 50.000 ton untuk batubara. Arah kemajuan tambang pada desain pit triwulan II ke arah selatan, barat lauttenggara terlihat dari desain pit, kemajuan penambangan mengikuti dip dan strike dari endapan seam batubara dimana kedalaman dan luas bukaan tambang desain pit bertambah tiap triwulannya (Gambar 4.5).

Desain geometri jenjang dan jalan didapatkan dari hasil rekomendasi konsultan tim geoteknik PT Duta Alam Sumatera yang sudah terealisasikan pada periode triwulan sebelumnya dan desain geometri jalan ditentukan pada penggunaan alat angkut terbesar yaitu dumptruck Tata Daeewo. Oleh karena itu, penentuan desain geometri jenjang dan jalan yang akan dirancang yaitu tinggi bench 10 meter, lebar bench 5 meter, kemiringan bench $45^{\circ}$ (single slope), $33^{\circ}$ (overall slope) berlaku terhadap highwall dan lowwall, sedangkan tahapan desain jalan dirancang untuk lebar jalan angkut lurus 10 meter, lebar jalan angkut pada tikungan 12 meter, dan grade (kemiringan) jalan maksimum $8 \%$.

Bentuk desain pit triwulan II memiliki luas area plan 5,20 Ha dengan elevasi $80 \mathrm{mdpl}$ ke arah barat daya, 70 mdpl ke barat daya, 60 mdpl ke arah barat daya dan penambahan fleet di elevasi 45 mdpl ke arah tenggara, serta untuk posisi sump berada di elevasi $35 \mathrm{mdpl}$ ke arah tenggara dengan kedalaman hingga elevasi $20 \mathrm{mdpl}$ sehingga didapatkan hasil cutting material overburden pada desain pit triwulan II sebesar 305.284 BCM, dan untuk batubara sebesar 52.029 ton dengan kualitas seam batubara A deangan SR 5,8:1. Oleh karena itu, desain pit yang telah dirancang dikategorikan dapat menunjang rencana produksi pada triwulan II tahun 2020. Desain pit pada triwulan II terlihat adanya pertambahan kedalamanan, yaitu 5 meter, 10 meter, 10 meter dan 5 meter pada arah tenggara dengan pertambahan luas bukaan pit sebesar 1,47 Ha dari desain pit triwulan I.

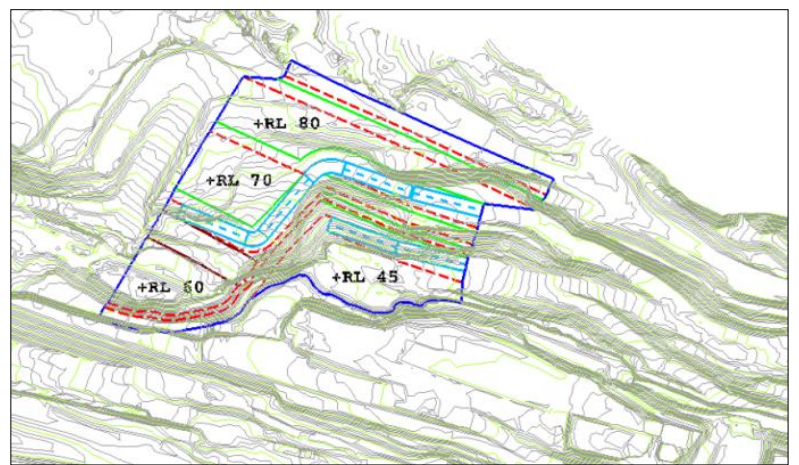

Gambar 4.5 Design Pit WEB Triwulan II

Desain pit yang telah dirancang selalu ada penambahan kedalaman elevasi di arah barat laut dan tenggara, dengan elevasi terendah pada design pit triwulan I elevasi terendah, yaitu pada $70 \mathrm{mdpl}$, lalu design pit triwulan II elevasi terendahnya adalah 45 mdpl. Hal ini disesuaikan terhadap endapan seam batubara A, yaitu pada pit WEB kegiatan penambangan dilakukan oleh kontraktor WEB (Wirasana Energi Bara) sehingga kemajuan tambang mengikuti jurus (penyebaran) 
batubara, dan berdasarkan kemiringan (dip) dari seam batubara (Gambar 4.2).

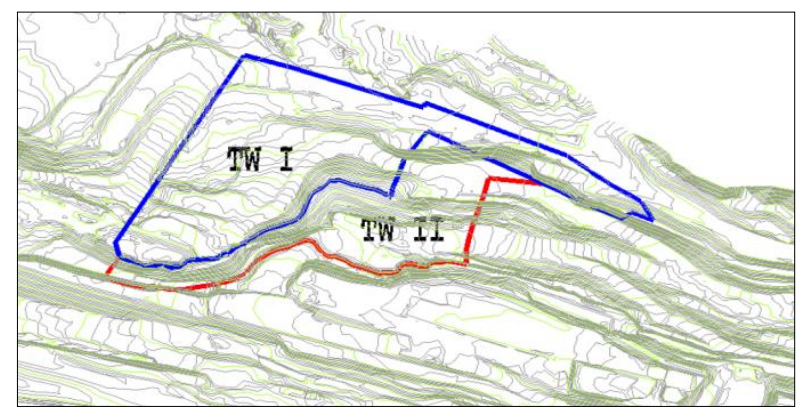

Gambar 4.6 Boundary kemajuan pit WEB

Desain pit pada penambangan batubara pit WEB Triwulan II sudah bisa memenuhi target rencana produksi material (overburden dan batubara) pada tahun 2020 sebesar 200.000 TON terlihat adanya penambahan luas bukaan penambangan seluas $1,47 \mathrm{Ha}$ kearah tenggara dengan penambahan kedalaman elevasi sedalam $15 \mathrm{~m}$ dan hasil dari cutting overburden dan batubara mendekati/mencapai terhadap nilai dari rencana produksi tiap triwulannya pada tahun 2020 seperti pada Tabel 4.1.

Tabel 4.4 Hasil design pit WEB Triwulan I

\begin{tabular}{|c|c|c|c|c|c|c|}
\multicolumn{1}{|c}{ dan II PT Duta Alam Sumatera } \\
\hline Periode & $\begin{array}{c}\text { Luas } \\
\text { Bukaan } \\
\text { Pit (Ha) }\end{array}$ & $\begin{array}{c}\text { OB } \\
\text { (BCM) }\end{array}$ & $\begin{array}{c}\text { BB } \\
\text { (TON) }\end{array}$ & SR & $\begin{array}{c}\text { RENCANA } \\
\text { PRODUKSI } \\
\text { OB (BCM) }\end{array}$ & $\begin{array}{c}\text { RENCANA } \\
\text { PRODUKSI } \\
\text { BB (TON) }\end{array}$ \\
\hline $\begin{array}{c}\text { Triwulan } \\
\text { I }\end{array}$ & 3,73 & 310.846 & 52.074 & $5,9: 1$ & 300.000 & 50.000 \\
\hline $\begin{array}{c}\text { Triwulan } \\
\text { II }\end{array}$ & 5,20 & 305.284 & 52.029 & $5,8: 1$ & 300.000 & 50.000 \\
\hline
\end{tabular}

c. Forecast plan kebutuhan alat gali-muat dan alat angkut

Penentuan forecast plan kebutuhan alat gali-muat dan angkut dengan mengolah data cycle time, data working hours plan of $O B$ removal, dan data physical avaibility yang disesuaikan terhadap data rencana produksi tahun 2020. Data cycle time diperlukan untuk mendapatkan produktivitas masing-masing alat mekanis yang diasumsi untuk overburden hauling distance $1.000 \mathrm{~m}$ dan untuk coal hauling distance $3.100 \mathrm{~m}$ yang disesuaikan terhadap waktu dilakukan penelitian (pengambilan data) dan jarak cukup terjauh dari front penambangan ke posisi stockpile dan disposal pada triwulan I. Produktifitas alat gali-muat dipengaruhi berdasarkan kapasitas bucket, faktor koreksi bucket, swell factor, effisiensi kerja, dan cycle time alat gali-muat, sedangkan produktifitas alat angkut berdasarkan jumlah pengisian alat gali-muat, kapasitas bucket, faktor koreksi bucket, swell factor, efisiensi kerja, dan cycle time alat angkut.

d. Forecast plan kebutuhan alat gali-muat dan alat angkut triwulan II tahun 2020

Hasil dari pengolahan data kemampuan alat berproduksi per jam dikalikan dengan total effective working hours triwulan II, didapatkan untuk pengupasan overburden dibutuhkan 2 unit alat gali-muat PC 400 dengan produksi alat sebesar 209.152 BCM dan alat angkut untuk overburden sebanyak 8 unit dumptruck CWB dengan produksi alat sebesar 201.370 BCM, sedangkan untuk fleet excavator Zaxis 470 dengan produksi alat sebesar 125.126 BCM dan untuk alat angkutnya sebanyak 4 unit dumptruck CWB dengan produksi alat sebesar 108.954 BCM.

Tabel 4.5 Forecast Plan Kebutuhan Alat GaliMuat dan Alat Angkut Triwulan II Tahun 2020

\begin{tabular}{|c|c|c|c|c|c|c|}
\hline \multicolumn{2}{|c|}{ Description } & Unit & $\begin{array}{c}\text { EWH } \\
\text { Total }\end{array}$ & Prod. Unit & Produksi & Prod. Plan \\
\hline \multirow{2}{*}{$\begin{array}{l}\text { Alat Gali- } \\
\text { Muat (OB) }\end{array}$} & $\begin{array}{c}\text { Exc } \\
\text { PC400 }\end{array}$ & 2 & \multirow{6}{*}{608} & $\begin{array}{c}172 \\
\mathrm{Bcm} / \mathrm{Jam}\end{array}$ & \multirow{2}{*}{$\begin{array}{c}334.278 \\
\mathrm{Bcm} / \text { Triw } \\
\text { ulan }\end{array}$} & \multirow{4}{*}{$\begin{array}{c}300.000 \\
\text { Bcm/Triwulan }\end{array}$} \\
\hline & $\begin{array}{c}\text { Exc } \\
\text { Zaxis } 470\end{array}$ & 1 & & $\begin{array}{c}205,8 \\
\mathrm{Bcm} / \mathrm{Jam}\end{array}$ & & \\
\hline $\begin{array}{l}\text { Alat Angkut } \\
\text { (OB) Load } \\
\text { PC400 }\end{array}$ & $\begin{array}{c}\text { DT } \\
\text { CWB }\end{array}$ & 8 & & $\begin{array}{c}41,40 \\
\mathrm{Bcm} / \mathrm{Jam}\end{array}$ & \multirow{2}{*}{$\begin{array}{c}310.324 \\
\text { Bcm/Triw } \\
\text { ulan }\end{array}$} & \\
\hline $\begin{array}{l}\text { Alat Angkut } \\
\text { (OB) Load } \\
\text { Zaxis } 470\end{array}$ & $\begin{array}{c}\text { DT } \\
\text { CWB }\end{array}$ & 4 & & $\begin{array}{c}44,8 \\
\mathrm{Bcm} / \mathrm{Jam}\end{array}$ & & \\
\hline $\begin{array}{l}\text { Alat Gali- } \\
\text { Muat (BB) }\end{array}$ & $\begin{array}{c}\text { Exc } \\
\text { PC400 }\end{array}$ & 1 & & $\begin{array}{c}184,12 \\
\text { Ton/Jam }\end{array}$ & $\begin{array}{c}55.972 \\
\text { Ton/Triw } \\
\text { ulan }\end{array}$ & 50.000 \\
\hline $\begin{array}{c}\text { Alat Angkut } \\
\text { (BB) }\end{array}$ & $\begin{array}{c}\text { DT } \\
\text { Daeewo }\end{array}$ & 5 & & $\begin{array}{c}33,83 \\
\text { Ton/Jam }\end{array}$ & $\begin{array}{c}51.442 \\
\text { Ton/Triw } \\
\text { ulan }\end{array}$ & Ton/Triwulan \\
\hline
\end{tabular}


Sedangkan forecast plan kebutuhan alat gali-muat untuk batubara dibutuhkan 1 unit Ex PC400 dengan produksi alat sebesar 55.972 ton dan untuk alat angkut batubara diperlukan 5 unit dump truck, yaitu 5 unit dump truck Daeewo dengan produksi alat sebesar 51.422 ton (Tabel 4.5). Jadi, forecast plan kebutuhan alat gali-muat dan alat angkut mampu menunjang rencana produksi triwulan II tahun 2020 sebesar 334.278 BCM untuk overburden dan 55.972 ton untuk batubara terlihat dari hasil produksi alat yang mencapai dalam pemenuhan rencana produksi.

Pada periode triwulan II dilakukan perencanaan penambahan alat dimana untuk menunjang design yang telah dibuat, dapat dilihat dari design triwulan II (Gambar 4.5), terdapat pelebaran boundary ke arah tenggara dan penambahan kedalaman elevasi dengan elevasi minimum $45 \mathrm{mdpl}$ guna menunjang rencana produksi pada pit WEB PT Duta Alam Sumatera periode triwulan II. Alat mekanis yang ditambahkan berupa 1 units excavator Komatsu PC400, 4 units dumptruck Nissan Diesel CWB450, dan 1 units Dozer Ripping D8R, guna untuk memenuhi target produksi pada triwulan II dikarenakan melihat dari kemampuan alat mekanis yang lama kurang optimal dalam beroperasi dikarena faktor umur alat yang sudah tua. Berdasarkan data ketercapaian produksi pada triwulan I PT Wirasana Energi Bara tidak memenuhi target produksi yang telah di tetapkan pihak PT Duta Alam Sumatera. Dapat dilihat dari tabel 4.6. dibawah ini.

Tabel 4.6 Produksi Aktual PT WEB Periode Triwulan I

\begin{tabular}{|c|c|c|c|c|}
\hline \multicolumn{2}{|c|}{ Overburden } & \multicolumn{2}{|c|}{ Coal Getting } & Total \\
\hline Unit Loader & $\stackrel{2}{5}$ & Units Hauler & 5 & $\begin{array}{l}\text { Units } \\
\text { Total }\end{array}$ \\
\hline $\begin{array}{c}\text { Excavator } \\
\text { Komatsu } \\
\text { PC400 }\end{array}$ & 1 & $\begin{array}{c}\text { Excavator } \\
\text { Komatsu } \\
\text { PC400 }\end{array}$ & 1 & 3 \\
\hline $\begin{array}{l}\text { Excavator } \\
\text { Hitachi }\end{array}$ & 1 & & & \\
\hline
\end{tabular}

\begin{tabular}{|c|c|c|c|c|}
\hline \multicolumn{2}{|c|}{ Overburden } & \multicolumn{2}{c|}{ Coal Getting } & Total \\
\hline Unit Loader & \multirow{\Xi}{\Xi}{} & Units Hauler & $\begin{array}{c}\text { Units } \\
\text { Total }\end{array}$ \\
\hline Zaxis 470 & 8 & $\begin{array}{c}\text { DT CWB } \\
450\end{array}$ & 5 & 13 \\
\hline $\begin{array}{c}\text { DT Tata } \\
\text { Daeewo }\end{array}$ & Volume Overburden (BCM) & $\begin{array}{c}\text { Volume } \\
\text { Coal } \\
\text { ton) }\end{array}$ \\
\hline \multicolumn{3}{|c|}{237.893} & 43.586 \\
\hline
\end{tabular}

Sumber: Enginering PT WEB

Berdasarkan tabel di atas maka peneliti dan pihak engineering PT WEB melakukan planning untuk menambah unit guna untuk menunjang produksi triwulan II agar tidak terjadi kembali ketidakcapaian produksi seperti pada triwulan I Tahun 2020.

Tabel 4.7 Penambahan Alat Mekanis Guna Menunjang Target Produksi Triwulan II Tahun 2020

\begin{tabular}{|c|c|c|}
\hline \multicolumn{2}{|c|}{ Description } & Units Total \\
\hline Unit Loader & Units & \\
\hline Exc Komatsu PC400 & 1 & \multirow{2}{*}{6 Units } \\
\hline Unit Hauler & Units & \\
\hline $\begin{array}{c}\text { DT Nissan Diesel } \\
\text { CWB 450 }\end{array}$ & 4 & \\
\hline Unit Support & Units & \\
\hline Dozzer Ripping D8R & 1 & \\
\hline
\end{tabular}

\section{e. Analisis faktor keamanan}

Design pit pada triwulan II dilakukan pengujian Faktor Keamanan (FK) kestabilan lereng pada dua section penampang dua dimensi. Desain geometri jenjang dan jalan didapatkan dari hasil rekomendasi konsultan tim geoteknik PT Duta Alam Sumatera yang sudah terealisasikan pada periode triwulan sebelumnya dan desain geometri jalan 
ditentukan pada penggunaan alat angkut terbesar yaitu dumptruck Tata Daeewo. Oleh karena itu, dengan penentuan desain geometri jenjang dan jalan yang akan dirancang yaitu tinggi bench 10 meter, lebar bench 5 meter, kemiringan bench $45^{\circ}$ (single slope), $33^{\circ}$ (overall slope) berlaku terhadap highwall dan lowwall, sedangkan tahapan desain jalan dirancang untuk lebar jalan angkut lurus 10 meter, lebar jalan angkut pada tikungan 12 meter, dan grade (kemiringan) jalan maksimum 8\% dengan menggunakan Software Slide V.6 dengan menggunakan metode Bishop.

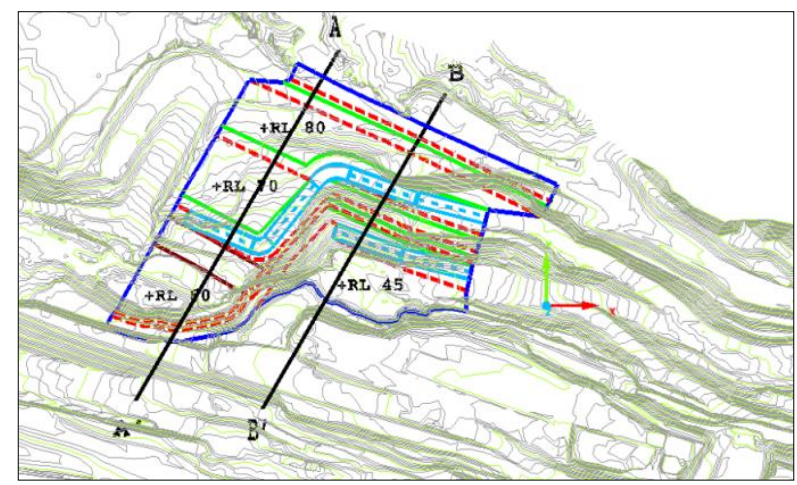

Gambar 4.7 Design Pit Section Triwulan II

Melalui software Slide V.6 dengan metode Bishop dengan menggunakan parameter kondisi sehingga didapat FK dengan nilai 6,074 pada section A - A', dan 2,909 pada section B - B', Sehingga lereng dikatakan aman.

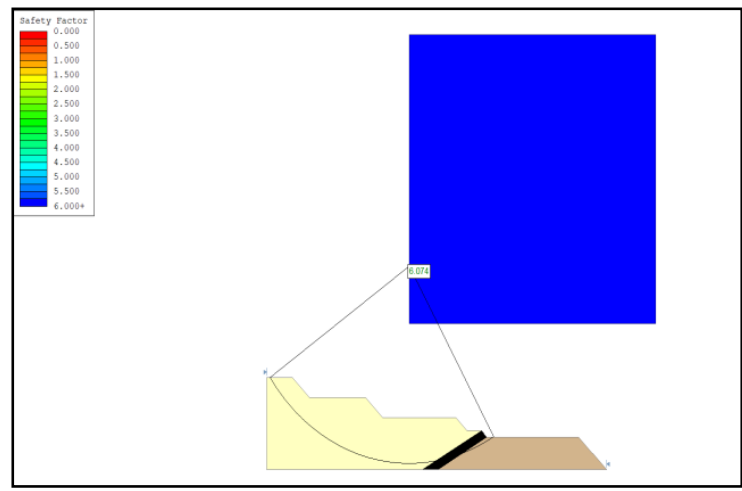

Gambar 4.8 Hasil Pengujian FK Section A-A'

Pengujian faktor keamanan kestabilan lereng pada periode Triwulan II terlihat FK kestabilan lereng pada section $A-A$ ' dengan nilai $\mathrm{FK}$ yang didapat 6,074 dalam kategori aman.

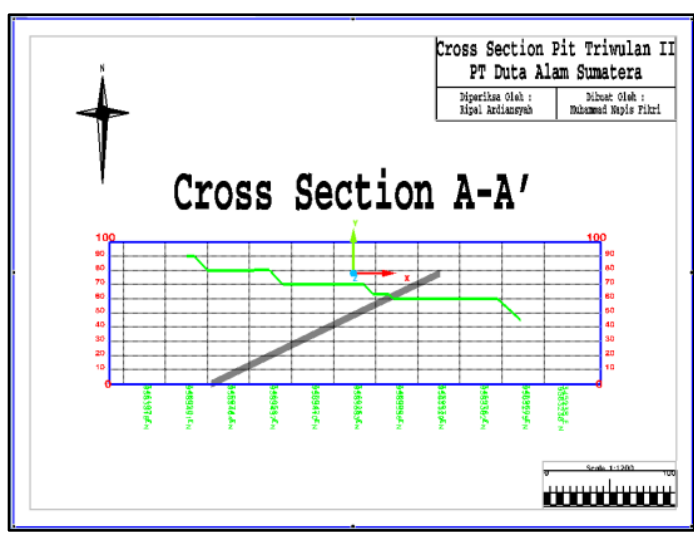

Gambar 4.9 Cross Section A-A'

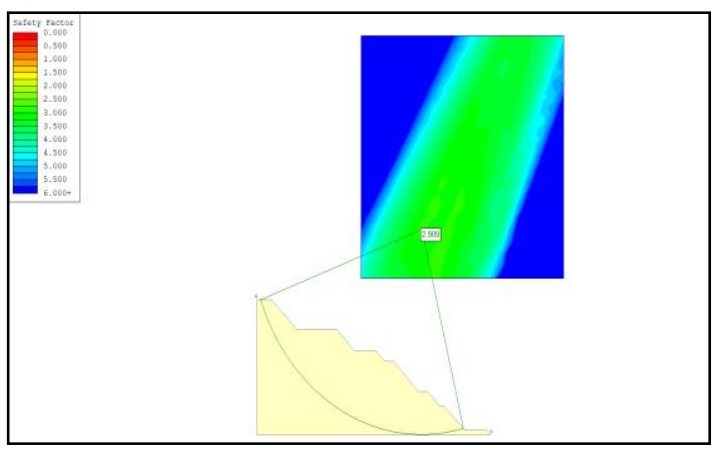

Gambar 4.10 Hasil Pengujian FK Section B-B'

Pengujian faktor keamanan kestabilan lereng pada periode Triwulan II terlihat FK kestabilan lereng pada section $B$ - $B$ ' dengan nilai FK yang didapat 2,909 dalam kategori aman.

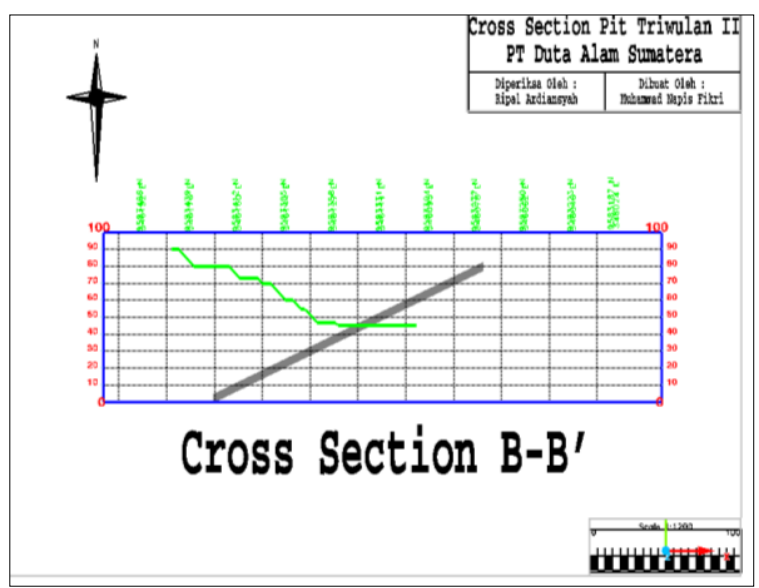

Gambar 4.11 Cross Section B-B' 


\section{KESIMPULAN}

Berdasarkan hasil dan pembahasan dapat diambil kesimpulan sebagai berikut:

1. Desain pit pada penambangan pit WEB Site PT Duta Alam Sumatera, pada triwulan II dengan elevasi 80 mdpl ke arah barat daya, 70 mdpl ke barat daya, 60 mdpl ke arah barat daya dan penambahan fleet di elevasi 45 mdpl ke arah tenggara, geometri didesain dengan tinggi bench $10 \mathrm{~m}$, lebar bench $5 \mathrm{~m}$, kemiringan bench $45^{\circ}$ (single slope), $33^{\circ}$ (overall slope), lebar pada jalan lurus $10 \mathrm{~m}$, pada tikungan $12 \mathrm{~m}$, kemiringan jalan (grade) maksimum $8 \%$, maka dengan geometri tersebut didapatkan hasil cutting overburden dan batubara untuk bentuk desain pit triwulan II memiliki luas area plan 5,20 Ha, desain pit triwulan II memiliki luas bukaan penambangan seluas 1,47 Ha dari desain pit triwulan I Tahun 2020 dengan hasil overburden sebesar 305.284 BCM dan batubara sebesar 52.029 ton yang didapatkan dari perhitungan menggunakan software Minescape 5.7.

2. Forecast plan kebutuhan alat gali-muat dan alat angkut yang digunakan untuk menunjang desain pit yang telah dirancang pada triwulan II tahun 2020 dengan rencana produksi 334.278 BCM untuk overburden dan 55.972 ton untuk batubara berdasarkan perhitungan produksi kemampuan alat dalam beroperasi, terdiri dari 3 unit excavator backhoe PC 400, 1 unit excavator Hitachi 470LC, 12 unit dumptruck Nissan Diesel CWB450, 5 unit dumptruck Tata Nouvus Daeewo dan 2 unit support Bulldozer D8R. Jadi, total alat loading 4 Unit, alat hauling 12 Unit, dan alat support 2 Unit. Dengan setting fleet 3 fleet overburden, dan 1 fleet batubara.

3. Analisis faktor keamanan pit design pada triwulan II dilakukan pengujian Faktor Keamanan (FK) melalui software Slide V.6 dengan metode Bishop. Sehingga didapat FK dengan nilai 6,074 pada section A - A', dan 2,909 pada section B - B' sehingga lereng dikatakan aman.

\section{DAFTAR PUSTAKA}

A, Dani Al Qadry. 2011. "Analisis Perbandingan Produktivitas Alat Angkut Hasil Simulasi Talpa untuk Penentuan Jumlah Alat Angkut Caterpillar 793 C di PT Newmont Nusa Tenggara Barat". Jurnal Universitas Pembangunan "Veteran" Yogyakarta: Yogyakarta.

Anisari, Rezky. 2012. Keserasian Alat Muat dan Angkut untuk Kecapaian Target Produksi Pengupasan Batuan Penutup pada PT Uniric Mega Persada Site Hajak Kabupaten Barito Utara Kalimantan Tengah. Jurnal INTEKNA. Tahun XII, No. 1, Mei 2012: 23-28.

Arief, Irwandy. 2003. Buku Ajar Perencanaan Tambang. Departemen Teknik Pertambangan ITB : Bandung.

Arif, Irwandy dan Gatut S. Adisoma. 2002. Perencanaan Tambang. Bandung: Institut Teknologi Bandung.

Baldus, C.F. Ambraw, dkk. 2012. Optimalisasi Produksi Alat Gali pada Penambangan Sirtu di PT Bintang Timur Lestari, Sorong, Papua. Papua. Jurnal Fakultas Teknik UNP.

Bowles, JE. 1989. Sifat-Sifat Fisik dan Geoteknis Tanah. Jakarta: Erlangga.

Chironis, Nicholas P. 1978. Coal Age Operating Handbook of Coal Surface Mining and Reclamation. McGraw-Hill, Inc : New York. 